\title{
Stress among Medical Students and Its Association with Substance Use and Academic Performance
}

\author{
Leta Melaku, ${ }^{1}$ Andualem Mossie, ${ }^{2}$ and Alemayehu Negash ${ }^{3}$ \\ ${ }^{1}$ Department of Biomedical Sciences, Asela College of Health Sciences, Arsi University, Asela, Ethiopia \\ ${ }^{2}$ Department of Biomedical Sciences, College of Health Sciences, Jimma University, Jimma, Ethiopia \\ ${ }^{3}$ Department of Psychiatry, College of Health Sciences, Jimma University, Jimma, Ethiopia
}

Correspondence should be addressed to Andualem Mossie; andualemm2000@gmail.com

Received 20 August 2015; Revised 31 October 2015; Accepted 15 November 2015

Academic Editor: Chandrashekhar T. Sreeramareddy

Copyright (c) 2015 Leta Melaku et al. This is an open access article distributed under the Creative Commons Attribution License, which permits unrestricted use, distribution, and reproduction in any medium, provided the original work is properly cited.

\begin{abstract}
Background. Chronic stress among medical students affects academic performance of students and leads to depression, substance use, and suicide. There is, however, a shortage of such research evidence in Ethiopia. Objective. We aimed to estimate the prevalence and severity of stress and its association with substance use and academic performance among medical students. Methods. A crosssectional survey was conducted on a sample of 329 medical students at Jimma University. Data were collected using the General Health Questionnaire (GHQ-12), Medical Students Stress Questionnaire (MSSQ-20), and Drug Abuse Surveillance Test (DAST). Data were analyzed using SPSS version 20.0. Logistic regression analysis and Student's $t$-test were applied. Results. The mean age of the respondents was 23.02 ( $\mathrm{SD}=2.074$ ) years. The current prevalence of stress was $52.4 \%$. Academic related stressor domain was the main source of stress among $281(88.6 \%)$ students. Stress was significantly associated with khat chewing [AOR $=3.03,95 \%$ CI $(1.17,7.85)]$, smoking $[\mathrm{AOR}=4.55,95 \% \mathrm{CI}(1.05,19.77)]$, and alcohol intake $[\mathrm{AOR}=1.93,95 \% \mathrm{CI}(1.03,3.60)]$. The prevalence of stress was high during the initial three years of study. Stress was significantly $(p=0.001)$ but negatively $(r=-0.273)$ correlated with academic achievement. Conclusion. Stress was a significant problem among medical students and had a negative impact on their academic performance. Year of study, income, and substance use were associated with stress. Counseling and awareness creation are recommended.
\end{abstract}

\section{Introduction}

Stress is the body's reaction to changes that requires physical, mental, or physiological adjustment [1]. Medical training is identified as full of stress and it is also observed that students undergo tremendous stress during various years of medical training $[2,3]$. For many students, first year brings dislocation of environment along with the realization that it is impossible to master education completely. This challenges many students' previous self-image as successful and capable of "perfect mastery" [4]. As second and third year proceed, these students are busy with preclinical courses, which are very vast in content. With a transition from preclinical to clinical training, students learn how to approach and handle patients. As a result, tension is reduced [5]. Students often also feel that they have insufficient knowledge and skill to practice medical training. During the fifth and the internship (sixth) years, students progressively assume more responsibility for patient care. Although students are expected to be increasingly competent, they continue to feel ignorant and anxious. They learn to cope with these feelings by appearing overconfident at times and by attempting to read "everything" and challenge everyone [6].

The study conducted by Sreeramareddy and coauthors 2007 revealed that most common sources of stress were high parental expectations, the vastness of the courses, overcrowded lecture halls, and dissatisfaction with class lectures [7]. The students also face other stressing factors like social, environmental, physical, and family problems, which may affect their academic performance and may result in substance use [8]. Research studies that have examined the sources of stress among medical students generally grouped into three main areas: academic pressures, social issues, and financial problems [9]. 
Another research report has indicated that stress causes high dropout rate of medical students [10]. Chronic stress may also lead to the development of anxiety and depression [11]. Other relevant researches revealed a total of $2.7 \%$ of Sweden medical students had made suicidal attempts due to stress [12]. Chronic exposure to stressful conditions leads to deterioration of academic performance, loss of memory, poor relationships with peers and family members, and overall dissatisfaction with life [13]. This chronic exposure can also lead to serious health problems like hypertension, heart attack and stroke, diabetes mellitus, and obesity, accelerates aging [14], impairs the immune system, suppresses fertility and digestive problems and loss of appetite, and increases anxiety and depression that finally lead to suicide [15]. Stress has also been found to be associated with sleep problems and lower academic performances [16]. Furthermore, it has also been linked to substances use and drug addiction [17].

Stress is very common among medical students across the globe. Medical students from different parts of the world have been found at risk of psychological stress, mental disorders, and decreased life satisfaction [18]. For example, the majority of medical students from universities in Mumbai, India [19], and Karachi, Pakistan [20], had faced stress at one time or another during their study period. Another study conducted on medical students of King Saud University, Saudi Arabia, revealed higher prevalence (57\%) of stress [21].

The excessive amount of stress in medical training predisposes students to be tempted to cheat on exams and to have difficulties in solving interpersonal conflicts, decreased attention, reduced concentration, loss of objectivity, increased incidence of errors, and improper behavior, such as negligence [22]. Furthermore, stress among students results in impaired judgments, absenteeism, self-medication, and addiction to substances such as khat chewing, cigarette smoking, and alcohol drinking [23].

Substance use in the present context means khat chewing, cigarette and shisha smoking, and alcohol drinking.

Khat (Catha edulis) is an evergreen plant grown in Ethiopia, Yemen, Kenya, Sudan, Madagascar, and South Africa [24]. The plant is commonly known as "khat" in literature. The psychostimulant effect of khat is due to the alkaloid chemical ingredient cathinone present in the fresh leaves of khat [25]. Cathinone is considered as a natural amphetamine [26]. Cathinone enhances the releases of catecholamine from their storage areas, resulting in CNS stimulation. The pattern of cathinone dependence is similar to that of amphetamine [27].

In Ethiopia, khat is commonly used for social recreation; drivers chew khat during long distance driving to keep awake [28]. Students in higher institutions chew khat to be alert and work hard during study periods with the assumption that khat improves academic performance [29]. There is also a specific usage of khat by the special section of the community: craftsmen and farmers use khat to reduce physical fatigue and traditional drug healers to heal ailments [30]. The central stimulating effect of cathinone is enhanced when it is combined with coffee or tea and cigarette smoking [31].

It was reported by Andualem and Zeleke that the prevalence of khat dependence among medical students was 33\% and the mean cumulative GPA of nonchewers was significantly higher than that of chewers [32].

Regular khat chewing is thought to be a predisposing factor for gastritis and peptic ulcer disease, mental illness, cardiac arrhythmia, tooth rust, and constipation [33]. The sympathomimetic effects of khat induce symptoms such as euphoria and hyperactivity, increased level of alertness, ability to concentrate, confidence, friendliness, contentment, and flow of ideas $[34,35]$. During khat chewing session, initially, there is an atmosphere of cheerfulness, optimism, and a general sense of well-being. After about 2 hours, tension, emotional instability, and irritability begin to appear later leading to feelings of stress and sluggishness [36, 37]. Khat is freely available in Ethiopia and is a highly valued export commodity to the neighboring countries.

However, there is no such a study conducted in Ethiopia to reveal the magnitude of stress among medical students. Therefore, we aimed to estimate prevalence and severity of stress and its association with substance use and academic achievement among medical students of Jimma University.

\section{Research Methods}

2.1. Study Design and Sampling Technique. The study was conducted at Jimma University main campus in April 130, 2013. Jimma University is one of the top universities in Ethiopia, located in Jimma Town (354 kilometers southwest of Addis Ababa). Jimma University trains high caliber professionals at undergraduate and postgraduate levels through its cherished and innovative community-based educational approach.

The medical curriculum of the School of Medicine at Jimma University takes six years. Medical students stay one semester on the premedical courses, two years on the preclinical courses, and three and half years on clinical practice.

A cross-sectional self-administered questionnaire survey was conducted on a sample of 329 medical students. The required sample size was estimated using single population proportion formula with $95 \% \mathrm{CI}, 5 \%$ margin of error, and $61.4 \%$ of the prevalence of stress [38]. The correction formula was used because the total number of medical students in the school was less than 10,000. Based on the academic year, stratified random sampling was employed after proportional allocation of sample size to each year level. Then, by using a systematic random sampling method, respondents were chosen every 4 students after randomly selecting one student based on their names list.

Sampling Technique. During the data collection period, there were $303,328,202,213,153$, and 135 undergraduate medical students enrolled in the first, second, third, fourth, fifth, and sixth year levels, respectively. The total number of students in these six categories was 1334 (1099 males and 235 females). In order to select a sample of 329 respondents from the population of 1,334 medical students, $75,81,50,52,38$, and 33 students were recruited by proportional allocation method from 1st to 6th year students, respectively. Respondents were 
selected from each category by simple random sampling technique.

2.2. Data Collection. Data collection was done using the General Health Questionnaire with 12 items (GHQ-12), Medical Students Stress Questionnaire with 20 items (MSSQ20), and Drug Abuse Surveillance Test (DAST) with certain modifications and sociodemographic questionnaire, where students were asked to respond genuinely to the study variables including their cumulative grade point average (CGPA). The questionnaire was pretested on seventeen randomly selected students who were not included in the study.

GHQ-12. It is one of the most widely used tools to screen psychiatric problems such as stress. These items in the questionnaire represent 12 manifestations of stress and medical students were asked to rate presence of each of these manifestations in themselves during the past six months before the study period. The study participants respond to each question by choosing one from four typical responses: "not at all", "no more than usual", "rather more than usual", and "much more than usual". A binary scoring method (0-0$1-1)$ is used to evaluate responses. Total scores of 4 and above were considered to be positive for stress [39].

MSSQ-20. It was used to identify sources of stress of medical students and it measures severity of stress caused by these stressors. Respondents were asked to rate the severity of stress by themselves during the past six months by choosing one among five alternatives: (1) causing no stress at all, (2) causing mild stress, (3) causing moderate stress, (4) causing high stress, and (5) causing severe stress. It was scored by assigning the value of $0-4$ for each of the respective responses. The tool consists of 20 items representing six stressor domains. These are academic related stressor (ARS), interpersonal related stressor (IRS), social related stressor (SRS), teaching and learning related stressor (TLRS), desire and drive related stressor (DDRS), and group activities related stressor (GARS).

Concerning the severity of stress as measured by MSSQ, those stressors have the mean score of $0-1.00$ that is mild stress. It indicates that it does not cause any stress. Even if it does, it just causes minimum stress. A score of 1.01-2.00 is moderate stress. It indicates that it reasonably causes stress. However, respondents can manage it well. A score of 2.013.00 is high stress. It indicates that it causes a lot of stress. In this case, emotion seems to be disturbed and daily activities are highly compromised due to stress. A score of 3.01-4.00 is severe stress. It indicates that it severely causes stress. It disturbs emotion badly and daily activities are severely compromised. Mild and moderate levels of stress are normal and high and severe levels of stress are abnormal [40].

2.3. Operational Definitions. The study focused mainly on three most common psychoactive substances: khat chewing, cigarette smoking, and alcohol drinking.
Khat Chewers/Cigarette Smokers/Alcohol Drinkers. This is the proportion of students who had ever chewed khat/smoked cigarette/drank alcohol, respectively.

Current Khat Chewers/Cigarette Smokers/Alcohol Drinkers. This is the proportion of youth who chewed khat/smoked cigarette/drank alcohol in the last 30 days preceding study time, respectively.

2.4. Data Analysis. After checking the collected data for completeness, it was double entered into Epi-data version 3.1 and exported into SPSS version 20.0 for analysis. Bivariate logistic regression was used to measure the association between independent variables with dependent variables. Multivariate logistic regression was used to identify predictors of stress. Statistical significance was accepted at $p<0.05$.

2.5. Ethical Issue. Ethical approval was obtained from Jimma University Ethical Review Committee. Written informed consent was taken from the students during data collection. The confidentiality was kept anonymous.

\section{Results}

3.1. Sociodemographic Characteristics and Their Association with Stress. There were 317 complete responses from the total of 329 sampled students with the participation rate of $96.4 \%$. Age of respondents ranged between 18 and 30 years with the mean of 23.02 ( $\mathrm{SD}=2.074)$ years. Two hundred forty (75.7\%) sampled students were males and 309 (97.5\%) of them were single in their marital status. One hundred forty-nine (47.0\%) of them had monthly income of 201-400 ETB (1\$USD $=21.00$ ETB, Ethiopian Birr). With regard to ethnicity and religions, $156(49.2 \%)$ of them were Oromo speakers and 157 (49.5\%) of them were Orthodox believers, respectively (Table 1). There was no significant association between the gender and stress in the present study.

The proportion of medical students who had symptoms of stress, according to the cutoff point of the General Health Questionnaire (GHQ-12), was 52.4\%. The current prevalence of the stress among different batches of medical students (1st to 6 th year students) was $58.3 \%, 57.0 \%, 48.9 \%, 56.6 \%, 50.0 \%$, and $25.0 \%$, respectively. In the present study, the highest prevalence of stress was observed in the first year students (58.3\%) as presented in Table 1.

3.2. Stressor Domains and Severity of Stress. According to MSSQ, among the six stressor domains, academic related stress (ARS) was the leading cause of stress on students. Two hundred eighty-one (88.7\%) medical students had ARS. Of these, $90(28.4 \%)$ had moderate stress, 128 (40.4\%) had high stress, and 63 (19.9\%) had severe stress. As shown in Table 2, teaching and learning related stressor (TLRS) and desire and drive related stressor (DDRS) were the second and third causes of stress. Two hundred thirty-eight (75.1\%) students had TLRS. Of these, $114(36.0 \%)$ had moderate stress and 94 (29.7\%) had high stress, while 30 (9.4\%) had severe stress. Similarly, 221 (69.7\%) had DDRS. Of these, 136 (42.9\%) 
TABLE 1: Association between stress and sociodemographic variables among medical students. Bivariate logistic regression analysis, $n=317$.

\begin{tabular}{|c|c|c|c|c|}
\hline \multirow{3}{*}{ Sociodemographic variables } & \multirow{3}{*}{$\begin{array}{l}\text { Total } \\
N(\%)\end{array}$} & \multicolumn{2}{|c|}{ Stress } & \multirow{3}{*}{ COR $(95 \%)$} \\
\hline & & Yes $(n=166)$ & No $(n=151)$ & \\
\hline & & $N(\%)$ & $N(\%)$ & \\
\hline \multicolumn{5}{|l|}{ Age } \\
\hline $15-19$ & $11(3.5)$ & $4(36.4)$ & $7(63.6)$ & $0.43(0.11-1.69)$ \\
\hline $20-24$ & $264(83.3)$ & $138(52.3)$ & $126(47.7)$ & $0.82(0.43-1.59)$ \\
\hline $25-30^{*}$ & $42(13.2)$ & $24(57.1)$ & $18(42.9)$ & 1.00 \\
\hline \multicolumn{5}{|l|}{ Sex } \\
\hline Male & $240(75.7)$ & $127(52.9)$ & $113(47.1)$ & $1.10(0.66-1.83)$ \\
\hline Female $^{*}$ & $77(24.3)$ & $39(50.6)$ & $38(49.4)$ & 1.00 \\
\hline \multicolumn{5}{|l|}{ Monthly income (ETB) } \\
\hline$\leq 200$ & $98(30.9)$ & $60(61.2)$ & $38(38.8)$ & $3.95(2.04-7.63)$ \\
\hline $201-400$ & $149(47.0)$ & $86(57.7)$ & $63(42.3)$ & $3.41(1.85-6.29)$ \\
\hline$>400^{*}$ & $70(22.1)$ & $20(28.6)$ & $50(71.4)$ & 1.00 \\
\hline \multicolumn{5}{|l|}{ Marital status } \\
\hline Single & $309(97.5)$ & $161(52.1)$ & $148(47.9)$ & $0.65(0.15-2.78)$ \\
\hline Married* & $8(2.5)$ & $5(62.5)$ & $3(37.5)$ & 1.00 \\
\hline \multicolumn{5}{|l|}{ Academic year level } \\
\hline First year & $72(22.7)$ & $42(58.3)$ & $30(41.7)$ & $4.20(1.58-11.14)$ \\
\hline Second year & $79(24.9)$ & $45(57.0)$ & $34(43.0)$ & $3.97(1.51-10.42)$ \\
\hline Third year & $47(14.8)$ & $23(48.9)$ & $24(51.1)$ & $2.88(1.03-8.05)$ \\
\hline Fourth year & $53(16.7)$ & $30(56.6)$ & $23(43.4)$ & $3.91(1.42-10.78)$ \\
\hline Fifth year & $38(12.0)$ & $19(50.0)$ & $19(50.0)$ & $3.00(1.03-8.71)$ \\
\hline Sixth year* & $28(8.8)$ & $7(25.0)$ & $21(75.0)$ & 1.00 \\
\hline \multicolumn{5}{|l|}{ Religion } \\
\hline Orthodox & $157(49.5)$ & $85(54.1)$ & $72(45.9)$ & $0.93(0.40-2.17)$ \\
\hline Muslim & $56(17.7)$ & $28(50.0)$ & $28(50.0)$ & $0.79(0.31-2.03)$ \\
\hline Protestant & $79(24.9)$ & $39(49.4)$ & $40(50.6)$ & $0.77(0.31-1.90)$ \\
\hline Others ${ }^{* ¥}$ & $25(7.9)$ & $14(56.0)$ & $11(44.0)$ & 1.00 \\
\hline \multicolumn{5}{|l|}{ Ethnicity } \\
\hline Oromo & $156(49.2)$ & $75(48.1)$ & 81 (51.9) & $0.69(0.31-1.56)$ \\
\hline Amhara & $81(25.6)$ & $40(49.4)$ & $41(50.6)$ & $0.73(0.31-1.74)$ \\
\hline Tigre & $28(8.8)$ & $21(75.0)$ & $7(25.0)$ & $2.25(0.72-7.01)$ \\
\hline Gurage & $24(7.6)$ & $14(58.3)$ & $10(41.7)$ & $1.05(0.35-3.17)$ \\
\hline Others ${ }^{* \dagger \dagger}$ & $28(8.8)$ & $16(57.1)$ & $12(42.9)$ & 1.00 \\
\hline
\end{tabular}

${ }^{*}$ Reference categories. ${ }^{¥}$ Catholic, Adventist, Waqefatta and Pagan. ${ }^{\dagger \dagger}$ Silte, Sidama, Kambata, Wolayita, and Somale. Current exchange rate: $\$ 1$ USD $=21.00$ ETB. $\mathrm{ETB}=$ Ethiopian Birr.

TABLE 2: Different stressor domains as sources of stress and severity of stress among medical students, $n=31$.

\begin{tabular}{|c|c|c|c|c|}
\hline \multirow[b]{2}{*}{ Stressor domains } & \multicolumn{4}{|c|}{ Severity of stress } \\
\hline & $\begin{array}{l}\text { Mild } \\
n(\%)\end{array}$ & $\begin{array}{c}\text { Moderate } \\
n(\%)\end{array}$ & $\begin{array}{l}\text { High } \\
n(\%)\end{array}$ & $\begin{array}{c}\text { Severe } \\
n(\%)\end{array}$ \\
\hline Academic related stressors (ARS) & $36(11.3)$ & $90(28.4)$ & $128(40.4)$ & $63(19.9)$ \\
\hline Group activities related stressors (GARS) & $200(63.1)$ & $84(26.5)$ & $27(8.5)$ & $6(1.9)$ \\
\hline Social related stressors (SRS) & $112(35.3)$ & $155(48.9)$ & $46(14.5)$ & $4(1.3)$ \\
\hline Interpersonal related stressors (IRS) & $172(54.3)$ & $92(29.0)$ & $39(12.3)$ & $14(4.4)$ \\
\hline Desire and derive related stressors (DRS) & $96(30.3)$ & $136(42.9)$ & $59(18.6)$ & $26(8.2)$ \\
\hline Teaching and learning related stressors (TLRS) & $79(24.9)$ & $114(36.0)$ & $94(29.7)$ & $30(9.4)$ \\
\hline
\end{tabular}


TABLE 3: Association between stress and academic performance (mean CGPA) among medical students, $n=317$.

\begin{tabular}{rrrcrc}
\hline & Mean CGPA \pm SD & $t$ & $p$ value & Mean difference & \multicolumn{2}{c}{$\begin{array}{c}\text { 95\% CI of the difference } \\
\text { Lower }\end{array}$} \\
\hline $\begin{aligned} \text { Stress } \\
\text { No }\end{aligned}$ & $3.41 \pm 0.31$ & 3.73 & 0.001 & 0.21 & 0.10 \\
Yes & $3.10 \pm 0.39$ & & & & 0.31 \\
\hline
\end{tabular}

TABLE 4: Correlation between stress and academic performance (last semester CGPA) among medical students, $n=317$.

\begin{tabular}{lcc}
\hline & $\begin{array}{c}\text { Last semester } \\
\text { cumulative GPA }\end{array}$ & Stress \\
\hline Last semester cumulative GPA & & \\
$\quad$ Pearson correlation & 1 & $-\mathbf{0 . 2 7 3 ^ { * * }}$ \\
$\quad$ Sig. (two-tailed) & & 0.001 \\
Stress & & \\
$\quad$ Pearson correlation & $-\mathbf{0 . 2 7 3 ^ { * * }}$ & 1 \\
$\quad$ Sig. (two-tailed) & 0.001 & \\
** Correlation is significant at the 0.01 level (two-tailed). CGPA $=$ cumulative $^{\text {grade point average. }}$
\end{tabular}

had moderate stress and 59 (18.6\%) had high stress while 26 (8.2\%) had severe stress.

3.3. Stress and Academic Achievement. An independent $t$-test was conducted to measure the degree of association between stress and academic achievement. There was significant difference between the mean CGPA of students who had stress and that of students without stress $[t=3.73$, mean difference $=0.21$, and $95 \%$ CI $(0.10,0.31)], p<0.001$ as shown in Table 3. Likewise, there is a significant $(p<0.001)$ but a negative $(r=-0.273)$ correlation between stress and last semester grade point average (CGPA) (Table 4$)$.

3.4. Stress and Substance Use. Concerning the association between substance use and stress, khat chewing, cigarette smoking, and alcohol drinking were common practices among students who had stress as presented in Table 5. Khat chewer students were 3.03 times more likely to have stress than nonchewers $[\mathrm{AOR}=3.03,95 \% \mathrm{CI}(1.17,7.85)]$. Cigarette smoker students were 4.55 times more likely to have stress than nonsmoker $[\mathrm{AOR}=4.55,95 \% \mathrm{CI}(1.05,19.77)]$. Alcohol drinkers were 1.93 times more likely to have stress than nondrinkers $[\mathrm{AOR}=1.93,95 \% \mathrm{CI}(1.03,3.60)]$ as shown in Table 6.

3.5. Risk Factors for Stress. Regarding the association between stress and monthly income, stress was markedly higher among low income students who earn $\leq 200 \mathrm{ETB} /$ month $[\mathrm{AOR}=2.52,95 \% \mathrm{CI}(1.15,5.50)]$ than high income students who earn $>400 \mathrm{ETB} /$ month as seen in Table 6 .

The highest prevalence of stress was observed among the 1st year students $(58.3 \%)$, followed by the 2 nd year $(57.0 \%)$, 3rd year $(48.9 \%)$, 4 th year $(56.6 \%)$, and 5 th year students $(50.0 \%)$. There was a significant association between the year of study and the stress levels. The odds ratios were 16.67 (1st year), 13.49 (2nd year), 9.12 (3rd year), 14.8 (4th year), and 7.25 (5th year), respectively, while the sixth year group was considered the reference category (Table 6). Higher prevalence of stress was recorded during the initial three years of courses than the last two years of courses.

\section{Discussion}

A high prevalence of stress among medical students indeed needed attention as it may impair the learning ability that may ultimately affect the quality of patient care they provide after graduation. The overall prevalence of stress in the present study was $52.4 \%$, which is almost similar to the prevalence reported by Abdulghani in Saudi Arabia (57\% [21]) and by Saipanish in Thailand (61.4\%) [38]. However, result of the present study is higher than the study reported by Firth in British (31.2\%) [41]. The possible reasons for the variability in the levels of stress could be due to certain differences in the curricula, teaching facilities, qualification and experience of the instructors, and the levels of care given to the students. Moreover, the differences in the level of stress among different reports could be due to the differences of the diagnostic instruments used as well. There is a big shortage of experienced instructors in both the preclinical and clinical disciplines in the study setting. Academic counseling is not a common practice in the present setup because of a large number of medical students and limited number of the faculties that may contribute to high prevalence of stress.

In the present study, as the year of study increases, prevalence of stress was decreasing. The possible explanations could be due to gradual adjustment to the learning environment and usually low failure rates in later years of the courses. The highest prevalence of stress was observed in first year students. This was because first year students started living in a new environment away from their family. This finding is in agreement with results of studies [21, 22, 41, 42], where students found medical training stressful during the 1st year, but the level of stress is minimized in subsequent years. The possible reason could be that senior students developed skills of how to manage their studies and, therefore, are better able to cope with stress than students in the early years.

According to the MSSQ, among six stressor domains, academic related stressor was the leading cause of stress followed by teaching-learning related stressor plus drives and desire related stressor. The study conducted by Sreeramareddy and coauthors 2007 in Nepal [7] strengthens the present finding that the most common sources of stress among medical students were the vastness of the courses and the frequency 
TABLE 5: Association between stress and substance use among medical students. Bivariate logistic regression analysis, $n=317$.

\begin{tabular}{|c|c|c|c|c|}
\hline \multicolumn{5}{|c|}{ Stress } \\
\hline \multirow[t]{2}{*}{ Substance use } & Total & Yes $(n=166)$ & No $(n=151)$ & COR $(95 \%)$ \\
\hline & $N(\%)$ & $N(\%)$ & $N(\%)$ & \\
\hline \multicolumn{5}{|l|}{ Khat chewing } \\
\hline Yes & $56(17.7)$ & $49(87.5)$ & $7(12.5)$ & $4.18(2.11-8.27)$ \\
\hline $\mathrm{No}^{*}$ & $261(82.3)$ & $144(55.2)$ & $117(44.8)$ & 1.00 \\
\hline \multicolumn{5}{|c|}{ Cigarette smoking } \\
\hline Yes & $30(9.5)$ & $27(90.0)$ & $3(10.0)$ & $6.83(2.32-20.10)$ \\
\hline $\mathrm{No}^{*}$ & $287(90.5)$ & $139(48.4)$ & $148(51.6)$ & 1.00 \\
\hline \multicolumn{5}{|c|}{ Alcohol drinking } \\
\hline Yes & $113(35.6)$ & $84(74.3)$ & $29(25.7)$ & $2.76(1.71-4.48)$ \\
\hline $\mathrm{No}^{*}$ & $204(64.4)$ & $82(40.2)$ & $122(59.8)$ & 1.00 \\
\hline
\end{tabular}

TABLE 6: Association between stress and predictor variables among medical students. Multivariate logistic regression analysis, $n=31$.

\begin{tabular}{|c|c|c|c|c|}
\hline \multirow{3}{*}{ Predictor variables } & \multirow{3}{*}{$\begin{array}{c}\text { Total } \\
N(\%)\end{array}$} & \multicolumn{2}{|c|}{ Stress } & \multirow{3}{*}{ AOR (95\%) } \\
\hline & & Yes $(n=166)$ & No $(n=151)$ & \\
\hline & & $N(\%)$ & $N(\%)$ & \\
\hline \multicolumn{5}{|c|}{ Monthly income (ETB) } \\
\hline$\leq 200$ & $98(30.9)$ & $60(61.2)$ & $38(38.8)$ & $2.52(1.15-5.50)$ \\
\hline $201-400$ & $149(47.0)$ & $86(57.7)$ & $63(42.3)$ & $2.73(1.34-5.54)$ \\
\hline$>400^{*}$ & $70(22.1)$ & $20(28.6)$ & $50(71.4)$ & 1.00 \\
\hline \multicolumn{5}{|l|}{ Year level } \\
\hline First year & $72(22.7)$ & $42(58.3)$ & $30(41.7)$ & $16.67(4.65-9.74)$ \\
\hline Second year & $79(24.9)$ & $45(57.0)$ & $34(43.0)$ & $13.49(3.90-47.22)$ \\
\hline Third year & $47(14.8)$ & $23(48.9)$ & $24(51.1)$ & $9.12(2.44-34.10)$ \\
\hline Fourth year & $53(16.7)$ & $30(56.6)$ & $23(43.4)$ & $14.80(4.05-54.15)$ \\
\hline Fifth year & $38(12.0)$ & $19(50.0)$ & $19(50.0)$ & $7.25(1.92-27.36)$ \\
\hline Sixth year* & $28(8.8)$ & $7(25.0)$ & $21(75.0)$ & 1.00 \\
\hline \multicolumn{5}{|l|}{ Khat chewing } \\
\hline Yes & $56(17.7)$ & $49(87.5)$ & $7(12.5)$ & $3.03(1.17-7.85)$ \\
\hline $\mathrm{No}^{*}$ & $261(82.3)$ & $117(44.8)$ & $144(55.2)$ & 1.00 \\
\hline \multicolumn{5}{|l|}{ Cigarette smoking } \\
\hline Yes & $30(9.5)$ & $27(90.0)$ & $3(10.0)$ & $4.55(1.05-19.77)$ \\
\hline $\mathrm{No}^{*}$ & $287(90.5)$ & $139(48.4)$ & $148(51.6)$ & 1.00 \\
\hline \multicolumn{5}{|l|}{ Alcohol using } \\
\hline Yes & $113(35.6)$ & $84(74.3)$ & $29(25.7)$ & $1.93(1.03-3.60)$ \\
\hline $\mathrm{No}^{*}$ & $204(64.4)$ & $82(40.2)$ & $122(59.8)$ & 1.00 \\
\hline Mean CGPA \pm SD & $317(100.0)$ & $3.10 \pm 0.39$ & $3.41 \pm 0.31$ & $0.10(0.05-0.21)$ \\
\hline
\end{tabular}

${ }^{*}$ Reference categories. ETB = Ethiopian Birr. Current exchange rate: $\$ 1 \mathrm{USD}=21.00 \mathrm{ETB}$.

CGPA = cumulative grade point average.

of examinations. The amount and complexity of the material to be learned in the first year of the medical schools are a major stressor to students. Additional supportive evidence was reported by Kholoud 2010 [43] and Siraj et al., 2014 in Malaysia [44] that high level of stress in the medical students can be attributed to the course workload, lack of leisure time, shortage of learning materials, and frequent examinations. Progressive assessments of anatomy, physiology, and biochemistry put the students in stress as they have to pass these courses to join the next higher level. The sources of stress that were found to be common for all students were the depth and breadth of the course contents and the teacher's attitude and qualification especially in the preclinical courses.

In the present study, those students who had lower monthly income were more likely stressed than students who had higher monthly income. This indicates that financial 
constraints could be an additional source of stress among students besides academic stressors. Despite the fact that food and dormitory services are provided to the students by the university, students need money for excursions, to print handouts, to buy dressings, and other basic necessities. This finding is in agreement with finding of Gushae, 1997, that reported medical students suffered from financial problems as a source of stress [45].

In the present study, there was a significant association between stress and students' academic achievement, but with negative correlation, indicating that when the level of stress increases, academic performance decreases.

Medical students are overloaded with a tremendous amount of information, especially during preclinical encounters. They have limited time to internalize all the information studied. The overload information creates a feeling of distress and disappointments, because they do not handle all topics covered and, therefore, are not successful during the examination period [22]. The excessive amount of stress in medical training predisposes students to have difficulties in solving problems and reduced concentration and finally develop depression [23]. Furthermore, stress among medical students can break the mental stability, impaired judgments, and absenteeism from class lesson. In effect, all those things compromise academic achievement of students.

This could be explained that excessive stress results in excessive secretion of a stress hormone cortisol that causes decrement in memory retrieval functions of hippocampus and amygdala due to complete blockage of glucocorticoid receptors.

As evidenced in the research report of Kuhlmann and coauthors 2005 [46] and Oei et al., 2007 [47], the effects of chronic stress on memory includes interference with a person's capacity to encode memory and to retrieve information. During times of stress, the body reacts by secreting stress hormones into the bloodstream. Oversecretion of a stress hormone cortisol affects memory negatively. In particular, the hippocampus, prefrontal cortex, and the amygdala are affected by cortisol. Under normal circumstances, the hippocampus regulates the production of cortisol through a negative feedback mechanism, because it has many receptors that are sensitive to cortisol. However, excess cortisol in case of chronic stress impairs the ability of the hippocampus to both encode and recall memories.

In the present study, the prevalence of alcohol consumption among medical students was $35.6 \%$, which is consistent with studies reported by Kalayu and coauthors (36.4\%) [48]. A bit higher (58\%) prevalence of alcohol consumption among medical students was reported by Seipone et al., 2013, at the University of Botswana [49].

Among alcohol user students in the present study, 74.3\% had stress symptoms. Alcohol drinking predisposes students to stress. Alcohol largely affects the brain and the endocrine system. There is a strong association between alcohol drinking and high level of cortisol, which is a stressor hormone. Alcohol is both a sedative and a depressant that affects the central nervous system. Alcohol changes levels of serotonin and other neurotransmitters in the brain. This can make stress worse $[50,51]$.

A related finding was reported by Britton 2004 [52] that there is a positive relationship between stress and alcohol use. Brady and Sonne 1999 [53] have described that people under chronic stress drinks more alcohol and eat less nutritious foods than nonstressed individuals. Alcohol actually increases the stress response by stimulating production of stress hormones. Alcohol directly activates the hypothalamus-pituitary-adrenal axis to produce excess cortisol. Drinking alcohol produces physiological stress; that is, some of the body's responses to alcohol are similar to its responses to other stressors. Yet, individuals also drink alcohol to relieve stress.

The prevalence of cigarette smoking among medical students was $9.5 \%$. In the present study, among cigarette smokers, $90 \%$ had stress symptoms. As reported by Parrott 1999 [54], smokers often mistakenly report that cigarettes help relieve feelings of stress, but the fact is it does not alleviate stress. However, the stress levels of adult smokers are slightly higher than those of nonsmokers. The level of stress was increased as they develop regular patterns of smoking and cessation of smoking reduces stress.

The prevalence of khat chewers among medical students was $17.7 \%$ in the present study. Among khat chewer students, $87.5 \%$ had manifested stress symptoms. This finding suggests that the active constituent of khat, cathinone, causes stress probably by stimulating secretion of a stress hormone cortisol in the body of chewers. Supporting evidence was reported by Al'Absi et al., 2013 [55], that the level of cortisol in saliva samples was higher among khat chewers than nonchewers.

\section{Conclusion}

To sum up, stress is a common problem among medical students. Year of study, monthly income, khat chewing, cigarette smoking, and alcohol intake were identified as risk factors of stress. The initial three years of the courses were more stressful for students than the last two years of the courses. Academic related stressors were main sources of stress in medical students. High level of stress was negatively implicated on academic performance. Awareness creation about the adverse effect of substance use, academic counseling in the first three years of the courses, and stress reduction interventions were recommended.

\section{Conflict of Interests}

The authors declare that there is no conflict of interests regarding the publication of this paper.

\section{Acknowledgments}

Authors are grateful to Jimma University for its financial support. Due thanks should be given to the respondents and data collectors. 


\section{References}

[1] B. Mannapur, A. S. Dorle, L. D. Hiremath, C. H. Ghattargi, U. Ramadurg, and K. R. Kulkarni, "A study of psychological stress in undergraduate medical students at SN Medical College, Bagalkot, Karnataka," Journal of Clinical and Diagnostic Research, vol. 4, no. 4, pp. 2869-2874, 2010.

[2] B. S. Mcewen, "Physiology and neurobiology of stress and adaptation: central role of the brain," Physiological Reviews, vol. 87, no. 3, pp. 873-904, 2007.

[3] C. A. Chew-Graham, A. Rogers, and N. Yassin, "I wouldn't want it on my CV or their records': medical students' experiences of help-seeking for mental health problems," Medical Education, vol. 37, no. 10, pp. 873-880, 2003.

[4] J. M. Rosenthal and S. Okie, "White coat, mood indigodepression in medical school," The New England Journal of Medicine, vol. 353, no. 11, pp. 1085-1088, 2005.

[5] G. Tchen, A. Carter, P. Gibbons, and P. McLaughlin, "What is the relationship between indicators of stress and academic performance in first year university students? A prospective study," Journal of Institutional Retrieve, vol. 40, no. 3, pp. 463473, 2001.

[6] M. T. Notman, C. C. Nadelson, and A. F. Poussaint, "Early clinical experience in behavioral science teaching," Journal of Medical Education, vol. 52, no. 8, pp. 683-685, 1977.

[7] C. T. Sreeramareddy, P. R. Shankar, V. S. Binu, C. Mukhopadhyay, B. Ray, and R. G. Menezes, "Psychological morbidity, sources of stress and coping strategies among undergraduate medical students of Nepal," BMC Medical Education, vol. 7, article 26, 2007.

[8] C. Fish and M. A. Nies, "Health promotion needs of students in a college environment," Public Health Nursing, vol. 13, no. 2, pp. 104-111, 1996

[9] P. P. Vitaliano, J. Russo, J. E. Carr, and J. H. Heerwagen, "Medical school pressures and their relationship to anxiety," Journal of Nervous and Mental Disease, vol. 172, no. 12, pp. 730-736, 1984.

[10] P. O'Regan, “Students under pressure," World of Irish Nursing, vol. 13, no. 9, pp. 16-18, 2005.

[11] S. M. Ko, E. H. Kua, and C. S. L. Fones, "Stress and the undergraduates," Singapore Medical Journal, vol. 40, no. 10, pp. 627-630, 1999.

[12] M. E. Dahlin and B. Runeson, "Burnout and psychiatric morbidity among medical students entering clinical training: a three year prospective questionnaire and interview-based study," BMC Medical Education, vol. 7, article 6, 2007.

[13] A. F. T. Arnsten, "Stress signalling pathways that impair prefrontal cortex structure and function," Nature Reviews Neuroscience, vol. 10, no. 6, pp. 410-422, 2009.

[14] J. E. Graham, L. M. Christian, and J. K. Kiecolt-Glaser, "Stress, age, and immune function: toward a lifespan approach," Journal of Behavioral Medicine, vol. 29, no. 4, pp. 389-400, 2006.

[15] S. M. Stewart, C. Betson, I. Marshall, C. M. Wong, P. W. H. Lee, and T. H. Lam, "Stress and vulnerability in medical students," Medical Education, vol. 29, no. 2, pp. 119-127, 1995.

[16] D. M. Kaufman, V. Day, and D. Mensink, "Stressors in 1st-year medical school: comparison of a conventional and problembased curriculum," Teaching and Learning in Medicine, vol. 8, no. 4, pp. 188-194, 1996.

[17] A. W. Yousafzai, S. Ahmer, E. Syed et al., "Well-being of medical students and their awareness on substance misuse: a crosssectional survey in Pakistan," Annals of General Psychiatry, vol. 8, article 8, 2009.
[18] K. Kjeldstadli, R. Tyssen, A. Finset et al., "Life satisfaction and resilience in medical school-a six-year longitudinal, nationwide and comparative study," BMC Medical Education, vol. 6, article 48, 2006.

[19] A. N. Supe, "A study of stress in medical students at Seth G. S. Medical College," Journal of Postgraduate Medicine, vol. 44, no. 1, pp. 1-6, 1998.

[20] B. T. Shaikh, A. Kahloon, M. Kazmi et al., "Students, stress and coping strategies: a case of Pakistani Medical School," Education for Health, vol. 17, no. 3, pp. 346-353, 2004.

[21] H. M. Abdulghani, "Stress and depression among medical students: a cross sectional study at a medical college in Saudi Arabia," Pakistan Journal of Medical Sciences, vol. 24, no. 1, pp. 12-17, 2008.

[22] M. S. B. Yusoff, A. F. Abdul Rahim, A. A. Baba, S. B. Ismail, M. N. Mat Pa, and A. R. Esa, "Prevalence and associated factors of stress, anxiety and depression among prospective medical students," Asian Journal of Psychiatry, vol. 6, no. 2, pp. 128-133, 2013.

[23] M. O’Rourke, S. Hammond, S. O’Flynn, and G. Boylan, “The medical student stress profile: a tool for stress audit in medical training," Medical Education, vol. 44, no. 10, pp. 1027-1037, 2010.

[24] P. Kalix, "Khat: a plant with amphetamine effects," Journal of Substance Abuse Treatment, vol. 5, no. 3, pp. 163-169, 1988.

[25] P. Nencini, M. C. Grassi, A. A. Botan, A. F. Asseyr, and E. Paroli, "Khat chewing spread to the Somali community in Rome," Drug and Alcohol Dependence, vol. 23, no. 3, pp. 255-258, 1989.

[26] A. S. Elmi, "Khat consumption and problems in Somalia," in Proceedings of the International Conference on Khat, pp. 17-21, Antananarivo, Madagascar, 1983.

[27] P. Kalix, "The pharmacology of khat," General Pharmacology, vol. 15 , no. 3, pp. 179-187, 1984.

[28] D. B. Ishraq and S. B. Jiri, "Khat habit and its health effect, a natural amphetamine," Biomedical Papers, vol. 148, no. 1, pp. 11$15,2004$.

[29] P. Hughes, Khat Chewing in Yemen, Abstracts of the Fourth International Institute on the Prevention and Treatment of Drug Dependence, International Council on Alcoholism and Addictions, Lausanne, Switzerland, 1973.

[30] P. Kalix, "The pharmacology of khat," in Proceedings of the International Symposium on Khat, pp. 69-73, Addis Ababa, Ethiopia, 1984.

[31] M. Amaha, "Clinical aspects of khat (Catha edulis Forsk)," in Proceedings of the International Symposium on Khat, pp. 77-83, 1983.

[32] M. Andualem and M. Zeleke, "Khat (Catha edulis Forsk) chewing, socio-demographic description and its effect on academic performance, Jimma University students," Ethiopian Medical Journal, vol. 42, no. 2, pp. 125-136, 2004.

[33] A. Atalay, K. Dereje, and G. Kullgren, "The prevalence and socio-demographic correlates of khat chewing in Butajira, Ethiopia," Acta Psychiatrica Scandinavica. Supplementum, vol. 397, pp. 84-91, 1999.

[34] E. Eshetu and T. Gedif, "Prevalence of khat, cigarette and alcohol use among students of technology and pharmacy, Addis Ababa University," Ethiopian Pharmaceutical Journal, vol. 24, no. 2, pp. 116-124, 2006.

[35] H. M. Ageely, "Prevalence of Khat chewing in college and secondary (high) school students of Jazan region, Saudi Arabia," Harm Reduction Journal, vol. 6, article 11, 2009. 
[36] D. Tekalign, M. Andualem, and T. Markos, "Khat chewing and mental distress: a community based study in Jimma City, Southwestern Ethiopia," Ethiopian Journal of Health Sciences, vol. 22, no. 1, pp. 37-45, 2011.

[37] M. Belew, D. Kebede, M. Kassaye, and F. Enquoselassie, "The magnitude of khat use and its association with health, nutrition and socioeconomic status," Ethiopian Medical Journal, vol. 38, no. 1, pp. 11-26, 2000.

[38] R. Saipanish, "Stress among medical students in a Thai medical school," Medical Teacher, vol. 25, no. 5, pp. 502-506, 2003.

[39] D. P. Goldberg, R. Gater, N. Sartorius et al., "The validity of two versions of the GHQ in the WHO study of mental illness in general health care," Psychological Medicine, vol. 27, no. 1, pp. 191-197, 1997.

[40] S. B. Y. Muhammad and A. Rahim, The Medical Student Stressor Questionnaire (MSSQ) Manual, vol. 1, KKMED Publications, Kelantan, Malaysia, 2010.

[41] J. Firth, "Levels and sources of stress in medical students," British Medical Journal, vol. 292, no. 6529, pp. 1177-1180, 1986.

[42] A. R. Abdallah and H. M. Gabr, "Depression anxiety and stress among first year medical students in an Egyptian public university," International Research Journal of Medicine and Medical Sciences, vol. 2, no. 1, pp. 11-19, 2014.

[43] A. H. Kholoud, "Prevalence of stressors among female medical students Taibah University, Saudi Arabia," Journal of Taibah University Medical Sciences, vol. 5, no. 2, pp. 110-119, 2010.

[44] H. H. Siraj, A. Salam, R. Roslan, N. A. Hasan, T. H. Jin, and M. N. Othman, "Stress and its association with the academic performance of undergraduate fourth year medical students at Universiti Kebangsaan Malaysia," The International Medical Journal Malaysia, vol. 13, no. 1, pp. 19-24, 2014.

[45] J. Gushae, "Financial worries part of education for memorial's medical students," Canadian Medical Association Journal, vol. 157, pp. 559-562, 1997.

[46] S. Kuhlmann, M. Piel, and O. T. Wolf, "Impaired memory retrieval after psychosocial stress in healthy young men," The Journal of Neuroscience, vol. 25, no. 11, pp. 2977-2982, 2005.

[47] N. Y. L. Oei, B. M. Elzinga, O. T. Wolf et al., "Glucocorticoids decrease hippocampal and prefrontal activation during declarative memory retrieval in young men," Brain Imaging and Behavior, vol. 1, no. 1-2, pp. 31-41, 2007.

[48] M. Kalayu, M. Andualem, and G. Yeshigeta, "Effect of substance use on academic achievement of health officer and medical students of Jimma University, Southwest Ethiopia," Ethiopian Journal of Health Sciences, vol. 19, no. 3, pp. 155-163, 2009.

[49] B. M. M. Seipone, G. Caroline, and B. Shyngle, "Stress and alcohol use among college students: a case of Molepolole College students," IOSR Journal Of Humanities And Social Science, vol. 8, no. 3, pp. 1-6, 2013.

[50] J. F. Thayer, M. Hall, J. J. Sollers III, and J. E. Fischer, "Alcohol use, urinary cortisol, and heart rate variability in apparently healthy men: evidence for impaired inhibitory control of the HPA axis in heavy drinkers," International Journal of Psychophysiology, vol. 59, no. 3, pp. 244-250, 2006.

[51] X. Dai, J. Thavundayil, S. Santella, and C. Gianoulakis, "Response of the HPA-axis to alcohol and stress as a function of alcohol dependence and family history of alcoholism," Psychoneuroendocrinology, vol. 32, no. 3, pp. 293-305, 2007.

[52] P. C. Britton, "The relation of coping strategies to alcohol consumption and alcohol-related consequences in a college sample," Addiction Research and Theory, vol. 12, no. 2, pp. 103114, 2004.
[53] K. T. Brady and S. C. Sonne, "The role of stress in alcohol use, alcoholism treatment, and relapse," Alcohol Research and Health, vol. 23, no. 4, pp. 263-271, 1999.

[54] A. C. Parrott, "Does cigarette smoking cause stress?" American Psychologist, vol. 54, no. 10, pp. 817-820, 1999.

[55] M. Al'Absi, N. S. Khalil, M. Al Habori, R. Hoffman, K. Fujiwara, and L. Wittmers, "Effects of chronic khat use on cardiovascular, adrenocortical, and psychological responses to stress in men and women," The American Journal on Addictions, vol. 22, no. 2, pp. 99-107, 2013. 

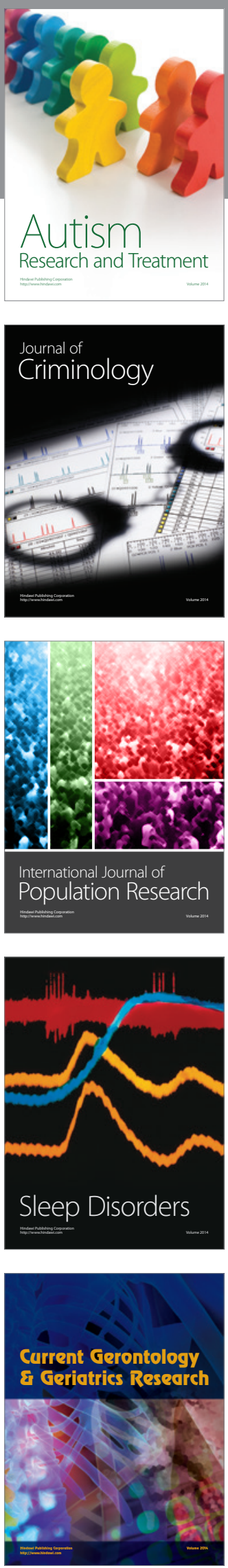
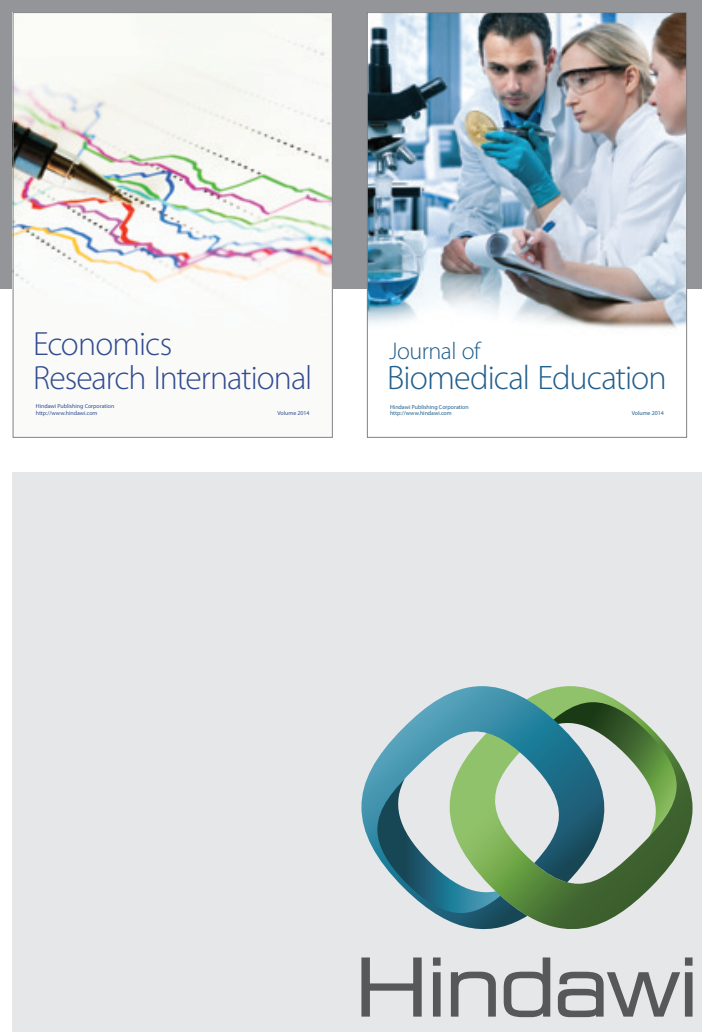

Submit your manuscripts at

http://www.hindawi.com
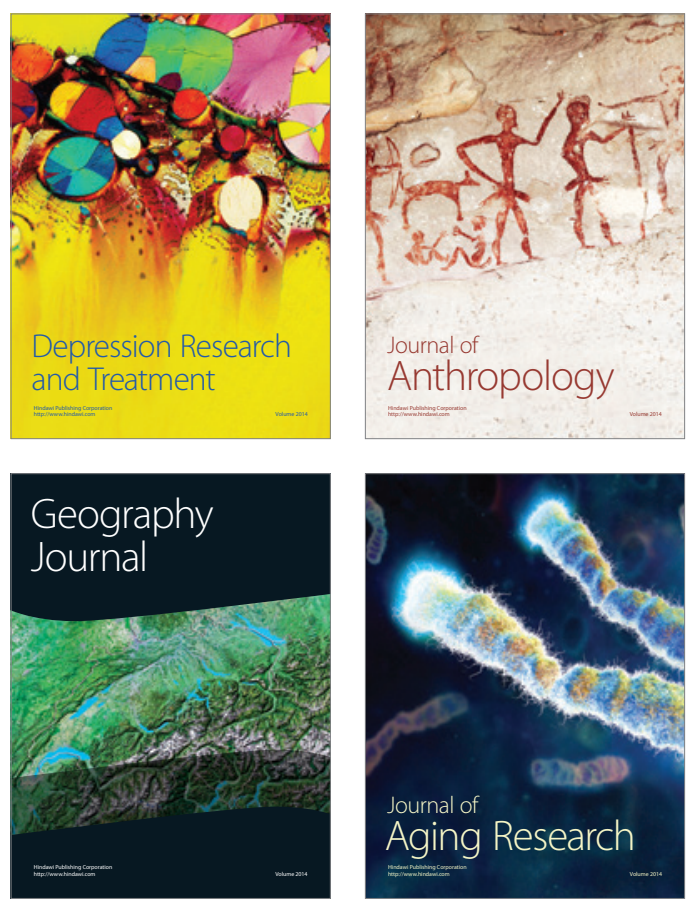
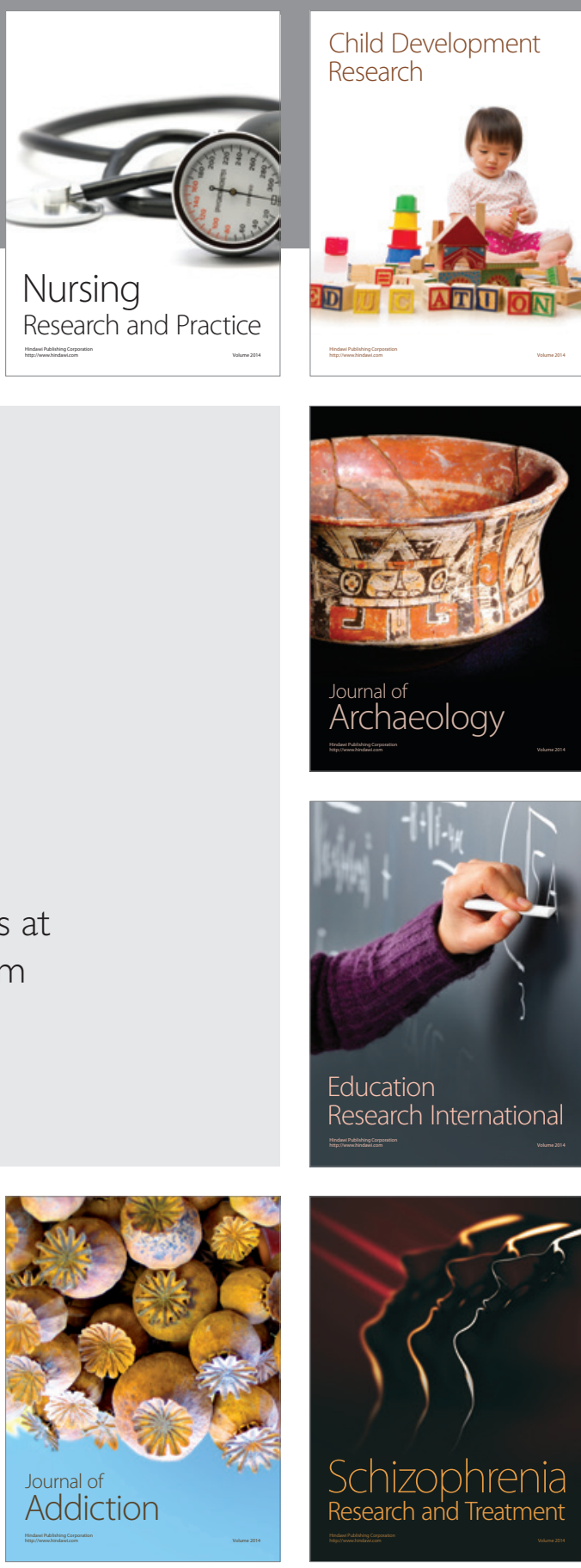

(D)
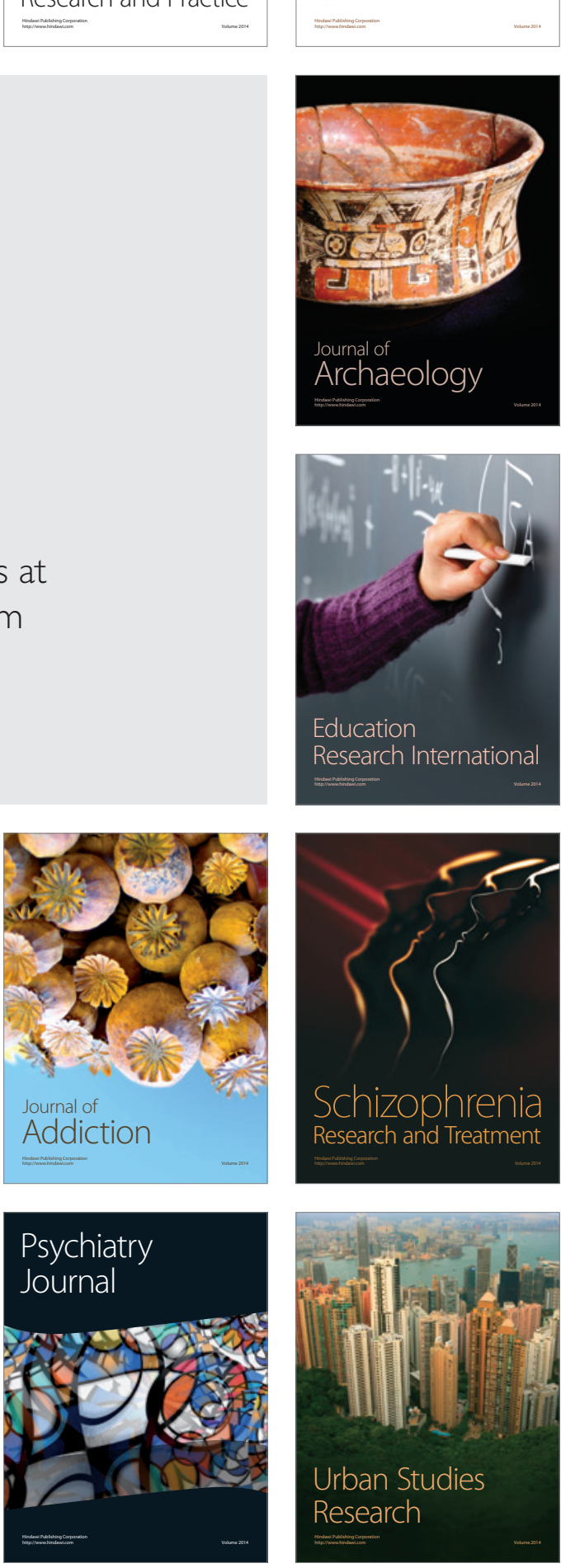